\title{
Lecithin nanoparticles enhance the cryosurvival of caprine sperm
} \author{
A. Mohammadi Sangcheshmeh ${ }^{\mathrm{c}}$ \\ ${ }^{a}$ Department of Animal Science, College of Agriculture and Natural Resource, University of Tehran, Karaj, Iran \\ ${ }^{\mathrm{b}}$ INDEGSAL and Dept. of Molecular Biology (Cell Biology), Universidad de León, León, Spain \\ ${ }^{\mathrm{c}}$ Department of Animal Science, College of Aboureihan, University of Tehran, Pakdasht, Iran
}

T. Nadri ${ }^{\text {a }}$, A. Towhidi ${ }^{\text {a, }}$, S. Zeinoaldini ${ }^{\text {a }}$, F. Martínez-Pastor ${ }^{\text {b }}$, M. Mousavi ${ }^{\text {a }}$, R. Noei ${ }^{\text {a }}$, M. Tar ${ }^{\text {a }}$,

\section{A R T I C L E IN F O}

\section{Article history:}

Received 11 May 2018

Received in revised form 13 April 2019

Accepted 18 April 2019

Available online $\mathrm{xxx}$

\section{Keywords:}

Nanoparticle

Sperm cryopreservation

Extender

Lecithin

Caprine

\begin{abstract}
A B S T R A C T
This study was designed to compare the effects on goat spermatozoa cryosurvival of nano-lecithin-based $(\mathrm{NL})$, lecithin-based (L) and egg yolk-based (EY) extenders. Ejaculates were collected from four fertile goats using artificial vagina and diluted with nine extenders. NL and $\mathrm{L}$ were tested at concentrations $1 \%$, $2 \%, 3 \%$ and $4 \%(\mathrm{w} / \mathrm{v})$, versus $15 \%(\mathrm{v} / \mathrm{v})$ egg yolk-based extender. Overall, sperm quality (higher motility, viability and HOST, and lower apoptosis) was higher for NL than for $\mathrm{L}$ treatments $(\mathrm{P}<0.05$ for most cases, except for $1 \%$ ). NL at $1 \%$ and especially at $4 \%$ showed lower motility and viability than $2 \%$ or $3 \%$ NL. NL at $2 \%$ achieved a better performance $(\mathrm{P}<0.05)$ than EY for VCL $(131.5 \pm 1.3$ vs. $120.3 \pm 1.9 \mu \mathrm{m} / \mathrm{s})$, VSL ( $43.9 \pm 1.5$ vs. $35.8 \pm 1.4 \mu \mathrm{m} / \mathrm{s})$, LIN ( $35.7 \pm 0.6$ vs. $29.3 \pm 0.8 \%)$, WOB $(47.0 \pm 0.5$ vs. $43.9 \pm 0.9 \%)$ and viability ( $66.4 \pm 1.7$ vs. $52.7 \pm 1.9 \%$ ). Late apoptotic spermatozoa were also lower in $2 \%$ NL compared to EY $(16.0 \pm 0.5$ vs. $26.3 \pm 1.1 \%, \mathrm{P}<0.001)$. EY and $2 \% \mathrm{NL}$ were compared in an IVF trial, with no significant differences in cleavage ( 68.8 vs. $70.8 \%$ ) or blastocyst ratios ( 21.3 vs. $20.8 \%$ ). In conclusion, using $2 \%$ nanolecithin in semen dilution could improve sperm cryosurvival of goat.
\end{abstract}

(C) 2019 .

\section{Introduction}

Cryopreservation can induce structural and functional damage to different compartments of spermatozoa [1] and the sensitivity of mammalian gametes to cold shock considerably reduces their resilience [2]. Besides, cell membranes are affected [3]. One of the first adverse events is disorganization of the membrane structure during cooling to $5^{\circ} \mathrm{C}$ [4]. Extenders are used to reduce the damage of cold shock. Therefore, the composition of the freezing extender is a crucial factor to protect spermatozoa.

Egg yolk is a major cryoprotectant for freezing semen from many species, other substances have superseded it. Egg yolk has a high between-lot variability, and also a risk of microbial contamination, which can lead to endotoxin production. This reduces the fertility of spermatozoa and increases the risk of disease transmission, of special concern in international semen exchange [5]. Soy lecithin, mainly composed of phosphatidylcholine [6], emerged as an alternative to components of animal origin. Many studies have confirmed the suitability of soy lecithin on sperm, including goat [7-10], ram [11-13], human [14] and cat [15], and several commercial formulations are currently available (e.g., Andromed, BIOXCell).

The use of lecithin in the form of micelles purposely produced could have several advantages by merely adding this cryoprotectant to the extender. Lecithin micelles are generated by spontaneous phos-

\footnotetext{
* Corresponding author.

Email address: atowhidi@ut.ac.ir (A. Towhidi)
}

pholipids molecular self-assembly, and they can be produced in a range of sizes and used as stable nanoparticles [16]. The micelles have high colloidal stability [17]. Thus, since nano micelles are in the nano range, probably, they can have a small particle size and high solubilization capacity. Therefore, a reduction in particle size of the lecithin micelles in the extender, potentially could allow for a more efficient effect, due to a higher surface to volume ratio. This size would allow for a better interaction or coating of spermatozoa, therefore reducing the damage of cold shock and other events during freezing-thawing.

In order to make stable micelle or nano-micelles, an external source of energy is necessary, such as heating or ultrasonication [17]. Currently, there are no studies about the effect of reducing the particle size of lecithin for the cryopreservation of goat spermatozoa. Therefore, the objectives of this study were producing nanoparticles of lecithin, testing different concentrations of nano-lecithin for protecting the quality of goat spermatozoa after freezing-thawing, and comparing them with the same concentrations of lecithin, and with $15 \%$ egg yolk to ensure its suitability. Considering the future testing of these extenders in the field, we conducted a preliminary IVF trial with the nano-lecithin extender yielding the highest post-thawing quality, to assess its performance compared to the standard egg yolk extender.

\section{Materials and methods}

Soybean lecithin (L-a-phosphatidylcholine (product number: P3644)) in this study was purchased from Sigma (St. Louis, MO, 
a)

$\begin{array}{rlllll} & & & \text { Diam. (nm) } & \text { \% Volume } & \text { Width (nm) } \\ \text { Z-Average (d.nm): } & 94.6 & \text { Peak 1: } & 76.7 & 95.3 & 27.2 \\ \text { Pdl: } & 0.222 & \text { Peak 2: } & 4540 & 4.7 & 1150 \\ \text { Intercept: } & 0.941 & \text { Peak 3: } & 0.00 & 0.0 & 0.00\end{array}$

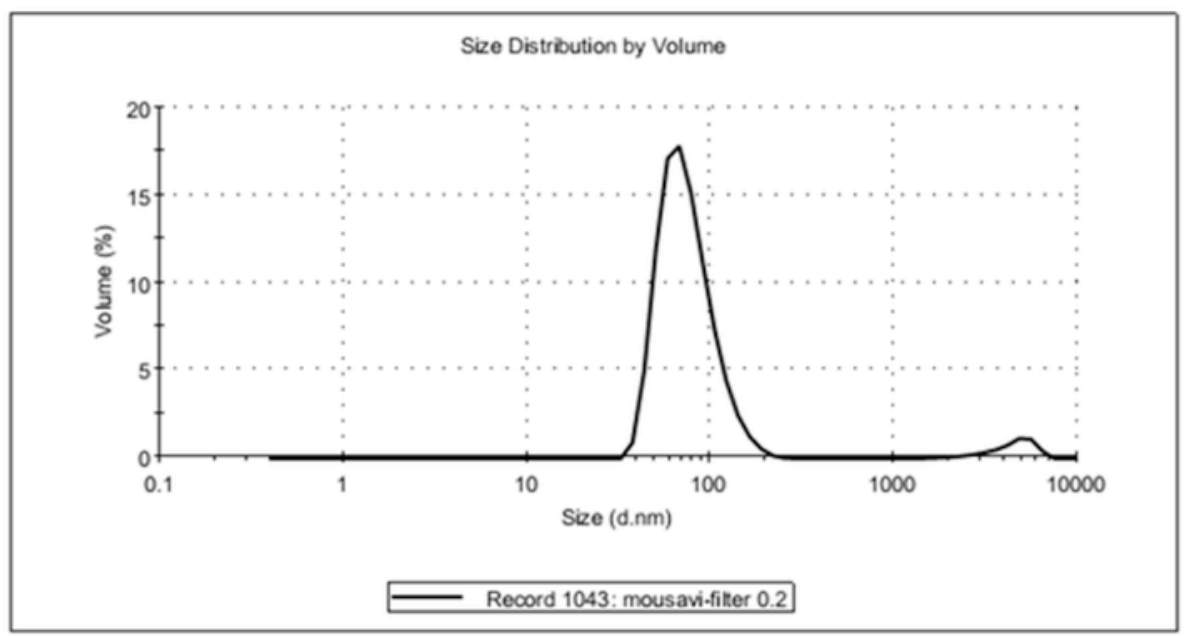

b)

Results

$\begin{array}{ccccc} & & \text { Mean }(\mathrm{mV}) & \text { Area }(\%) & \text { Width }(\mathrm{mV}) \\ \text { Zeta Potential }(\mathrm{mV}):-16.7 & \text { Peak 1: } & -16.7 & 100.0 & 11.0 \\ \text { Zeta Deviation }(\mathrm{mV}): 11.0 & \text { Peak 2: } 0.00 & 0.0 & 0.00 \\ \text { Conductivity }(\mathrm{mS} / \mathrm{cm}): 5.79 & \text { Peak 3: } 0.00 & 0.0 & 0.00\end{array}$

Zeta Potential Distribution

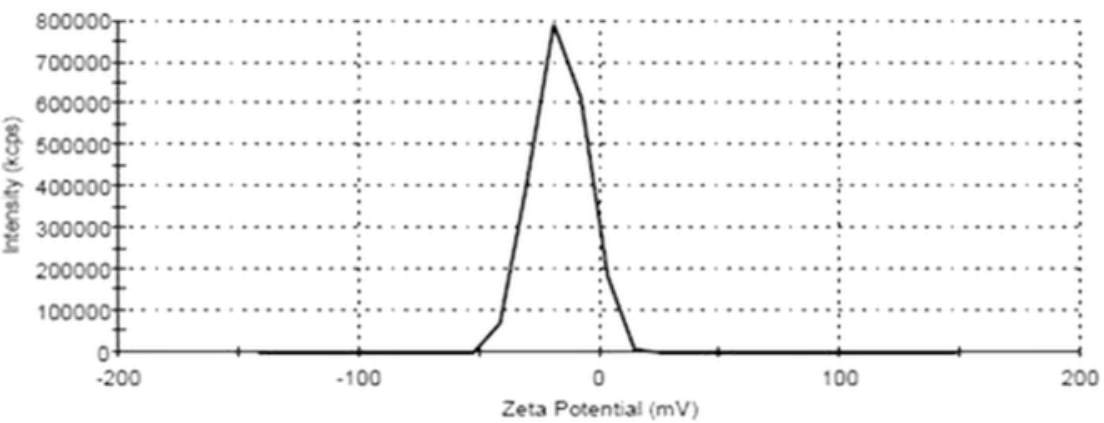

Record 1044, Tar_fivers

Fig. 1. 
a)

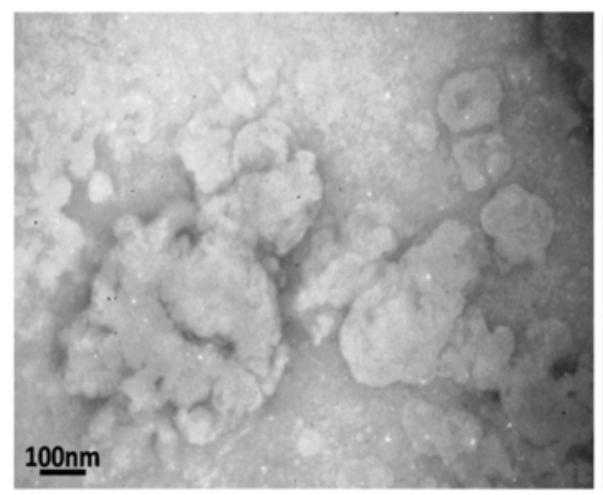

b)

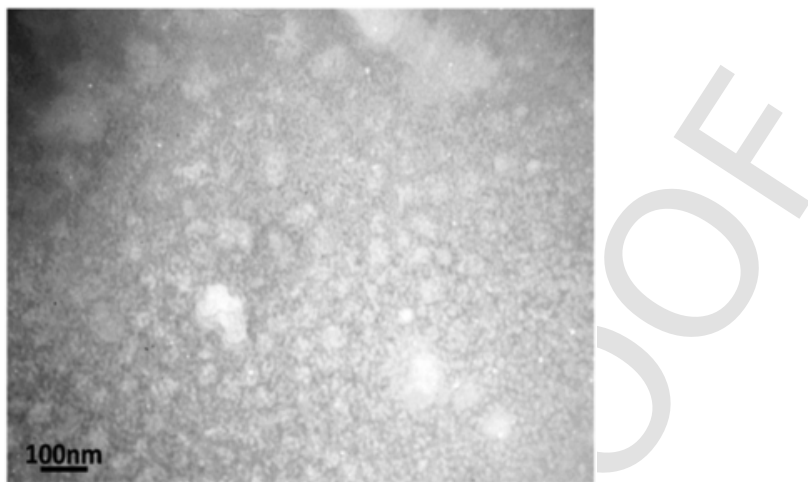

Fig. 2.

Table 1

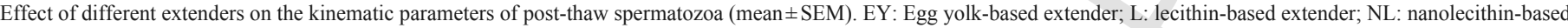
extender; $1-4: \%$ of $\mathrm{L}$ or $\mathrm{NL}$ in each extender.

\begin{tabular}{|c|c|c|c|c|c|c|}
\hline & $\mathrm{VAP}(\mu \mathrm{m} / \mathrm{s})$ & $\operatorname{VSL}(\mu \mathrm{m} / \mathrm{s})$ & LIN (\%) & STR (\%) & WOB (\%) & $\mathrm{ALH}(\mu \mathrm{m})$ \\
\hline L1 & $47.5 \pm 2.4^{\mathrm{a} \beta}$ & $30.8 \pm 1.2^{\mathrm{a} \beta *}$ & $26.1 \pm 0.6^{\mathrm{a} *}$ & $57.5 \pm 3.7$ & $42.2 \pm 0.6^{\mathrm{a}}$ & $2.76 \pm 0.1^{\mathrm{a}}$ \\
\hline L2 & $37.9 \pm 2.9^{\mathrm{b} \beta * * *}$ & $27.8 \pm 2.1^{\mathrm{ab} \beta * *}$ & $21.3 \pm 1.2^{\mathrm{b} \beta * * *}$ & $58.1 \pm 2.4$ & $39.4 \pm 0.9^{\mathrm{b} \beta * * *}$ & $2.01 \pm 0.2^{\mathrm{ab} \beta * *}$ \\
\hline L3 & $35.2 \pm 2.1^{\mathrm{b} \beta * * *}$ & $25.7 \pm 1.3^{\mathrm{b} \beta * * *}$ & $21.6 \pm 1.0^{\mathrm{b} \beta * * *}$ & $56.4 \pm 4.9$ & $39.3 \pm 0.6^{\mathrm{b} \beta * * *}$ & $1.93 \pm 0.2^{\mathrm{ab} \beta * *}$ \\
\hline L4 & $35.6 \pm 3.4^{\mathrm{b} \beta * * *}$ & $24.8 \pm 1.3^{\mathrm{b} \beta * * *}$ & $21.0 \pm 0.6^{\mathrm{b} \beta * * *}$ & $57.3 \pm 1.8$ & $38.0 \pm 0.9^{\mathrm{b} \beta * * *}$ & $1.58 \pm 0.2^{\mathrm{b} * * *}$ \\
\hline NL1 & $48.2 \pm 0.6^{\mathrm{a} \alpha}$ & $33.8 \pm 1.2^{\mathrm{a} \alpha}$ & $28.5 \pm 1.1^{\mathrm{a}}$ & $57.2 \pm 2.9$ & $43.9 \pm 0.9^{\mathrm{a}}$ & $2.82 \pm 0.2$ \\
\hline NL2 & $60.5 \pm 2.7^{b \alpha}$ & $43.9 \pm 1.5^{\mathrm{b} \alpha * *}$ & $35.7 \pm 0.6^{\mathrm{b} \alpha * * *}$ & $53.1 \pm 2.2$ & $47.0 \pm 0.5^{\mathrm{b} \alpha * *}$ & $3.90 \pm 0.1^{\alpha}$ \\
\hline NL3 & $54.6 \pm 2.2^{\mathrm{b} \alpha}$ & $39.2 \pm 2.4^{\mathrm{ab} \alpha}$ & $32.3 \pm 0.3^{\mathrm{b} \alpha *}$ & $51.1 \pm 2.2$ & $45.4 \pm 0.3^{\mathrm{a} \alpha}$ & $2.99 \pm 0.1^{\alpha}$ \\
\hline NL4 & $49.0 \pm 2.5^{\mathrm{a} \alpha}$ & $35.3 \pm 2.4^{\mathrm{a} \alpha}$ & $27.3 \pm 1.5^{\mathrm{a} \alpha}$ & $56.9 \pm 1.2$ & $43.5 \pm 0.7^{\mathrm{a} \alpha}$ & $2.52 \pm 0.4$ \\
\hline EY & $52.7 \pm 1.4$ & $35.8 \pm 1.4$ & $29.3 \pm 0.8$ & $56.6 \pm 3.0$ & $43.9 \pm 0.9$ & $3.18 \pm 0.2$ \\
\hline
\end{tabular}

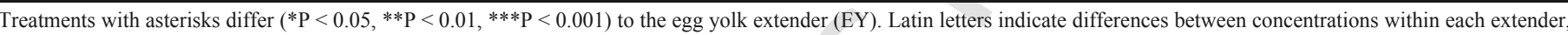
and greek letters differences between extenders within each concentration $(\mathrm{P}<0.05)$.

\begin{tabular}{llllll}
\hline & $\begin{array}{l}\text { Total } \\
\text { motility } \\
(\%)\end{array}$ & $\begin{array}{l}\text { Progressive } \\
\text { motility } \\
(\%)\end{array}$ & $\begin{array}{l}\text { Viable } \\
\text { spermatozoa } \\
(\mathrm{E} / \mathrm{N})(\%)\end{array}$ & $\begin{array}{l}\text { HOS test } \\
(\%)\end{array}$ & $\begin{array}{l}\text { Normal } \\
\text { spermatozoa } \\
(\%)\end{array}$ \\
\hline L1 & $60.1 \pm 1.5$ & $35.5 \pm 1.1$ & $64.9 \pm 1.5$ & $59.8 \pm 2.2$ & $68.1 \pm 2.5$ \\
L2 & $54.1 \pm 1.5$ & $33.0 \pm 1.1$ & $55.7 \pm 1.5$ & $53.5 \pm 2.2$ & $69.7 \pm 2.5$ \\
L3 & $51.5 \pm 1.5$ & $31.0 \pm 1.1$ & $52.2 \pm 1.5$ & $49.1 \pm 2.2$ & $69.3 \pm 2.5$ \\
L4 & $49.9 \pm 1.5$ & $31.0 \pm 1.1$ & $50.5 \pm 1.5$ & $47.4 \pm 2.2$ & $58.2 \pm 2.5$ \\
NL1 & $62.5 \pm 1.5$ & $46.1 \pm 1.1$ & $63.1 \pm 1.5$ & $61.1 \pm 2.2$ & $72.6 \pm 2.5$ \\
NL2 & $66.3 \pm 1.5$ & $47.8 \pm 1.1$ & $68.8 \pm 1.5$ & $65.9 \pm 2.2$ & $75.0 \pm 2.5$ \\
NL3 & $64.0 \pm 1.5$ & $46.3 \pm 1.1$ & $64.5 \pm 1.5$ & $62.2 \pm 2.2$ & $76.0 \pm 2.5$ \\
NL4 & $51.2 \pm 1.5$ & $42.8 \pm 1.1$ & $52.8 \pm 1.5$ & $49.6 \pm 2.2$ & $71.8 \pm 2.5$ \\
EY & $63.3 \pm 1.5$ & $47.1 \pm 1.1$ & $46.0 \pm 1.5$ & $62.1 \pm 2.2$ & $76.1 \pm 2.5$ \\
\hline
\end{tabular}

USA), and other chemicals were purchased from Merck (Darmstadt, Germany).

\subsection{Animals}

Four mature Mahabadi bucks (aged 3-4 years) of good fertility were used in the study, collecting 24 ejaculates by artificial vagina twice a week ( 6 ejaculates/male) during the breeding season. Volume ranged $0.75-2 \mathrm{~mL}$. Criteria for accepting an ejaculate were: Concentration $>3 \times 10^{9}$ spermatozoa $/ \mathrm{mL}$, percentage of sperm motility $>70 \%$, and abnormal spermatozoa $<10 \%$. The semen from the four bucks were pooled in each session to eliminate individual differences, therefore using 6 semen batches in the study. Each pooled sample was split into nine aliquots and diluted with the different extenders.
Table 2

Effect of the exenders on the percent of viable, apoptotic and necrotic spermatozoa according to the Annexin-V/PI staining (mean \pm SEM). EY: Egg yolk-based extender; L: lecithin-based extender; NL: nanolecithin-based extender; 1-4: \% of L or NL in each extender.

\begin{tabular}{lllll}
\hline & $\begin{array}{l}\text { Viable (\%An- } \\
\text { /PI- })\end{array}$ & $\begin{array}{l}\text { Early apoptotic } \\
(\% \text { An+/PI- }\end{array}$ & $\begin{array}{l}\text { Late apoptotic } \\
(\text { An+/PI+) }\end{array}$ & $\begin{array}{l}\text { Necrotic } \\
(\text { An-/PI+) }\end{array}$ \\
\hline L1 & $60.2 \pm 1.1^{\mathrm{a} * *}$ & $15.8 \pm 0.3^{\mathrm{a}}$ & $19.3 \pm 1.2^{\mathrm{a} * *}$ & $4.5 \pm 1.0$ \\
L2 & $54.5 \pm 1.9^{\mathrm{ab} \beta}$ & $20.0 \pm 1.0^{\mathrm{ab}}$ & $19.7 \pm 0.7^{\mathrm{a} \alpha * *}$ & $5.7 \pm 1.6$ \\
L3 & $39.6 \pm 2.0^{\mathrm{c} \beta * * *}$ & $29.7 \pm 4.0^{\mathrm{c} * * *}$ & $26.5 \pm 1.4 \mathrm{c}$ & $4.1 \pm 0.5^{\beta}$ \\
L4 & $30.4 \pm 1.1^{\mathrm{d} \beta * * *}$ & $23.4 \pm 1.9^{\mathrm{bc} \beta *}$ & $44.0 \pm 1.1^{\mathrm{d} \alpha * *}$ & $2.1 \pm 0.3^{\beta}$ \\
NL1 & $51.7 \pm 2.1 \mathrm{a}$ & $20.4 \pm 1.9 \mathrm{a}$ & $23.1 \pm 1.6 \mathrm{a}$ & $4.6 \pm 1.1$ \\
NL2 & $66.4 \pm 1.7^{\mathrm{b} \alpha * *}$ & $15.3 \pm 0.4^{\mathrm{b}}$ & $16.0 \pm 0.5^{\mathrm{b} \beta * * *}$ & $2.2 \pm 1.0$ \\
NL3 & $55.6 \pm 1.6^{\mathrm{a} \alpha}$ & $18.0 \pm 0.7^{\mathrm{a}}$ & $23.2 \pm 1.3^{\mathrm{a}}$ & $3.0 \pm 0.3^{\alpha}$ \\
NL4 & $38.8 \pm 1.8^{\mathrm{c} \alpha * * *}$ & $30.6 \pm 0.5^{\mathrm{c} \alpha * * *}$ & $25.9 \pm 2.4^{\mathrm{a} \beta}$ & $4.6 \pm 0.3^{\alpha}$ \\
EY & $52.7 \pm 1.9$ & $18.0 \pm 0.5$ & $26.3 \pm 1.1$ & $2.9 \pm 0.7$ \\
\hline
\end{tabular}

Treatments with asterisks differ $(* \mathrm{P}<0.05, * * \mathrm{P}<0.01, * * * \mathrm{P}<0.001)$ to the egg yolk extender (EY). Latin letters indicate differences between concentrations within each extender, and greek letters differences between extenders within each concentration $(\mathrm{P}<0.05)$.

\subsection{Extender preparation}

The basic extender was made of Tris $253.42 \mathrm{mM}$, fructose $69.93 \mathrm{mM}$, and citric acid $87.44 \mathrm{mM}$. The osmolarity and $\mathrm{pH}$ were set at $420 \mathrm{mOsm} / \mathrm{kg}$ and 7.2 , respectively. Glycerol was added at $5 \%(\mathrm{v} /$ v) to this base extender. This extender was supplemented with egg yolk, lecithin or nano-lecithin in order to make the extenders tested in this study. The egg-yolk extender (EY) contained 15\% egg yolk (v/v). 
a) Total motility

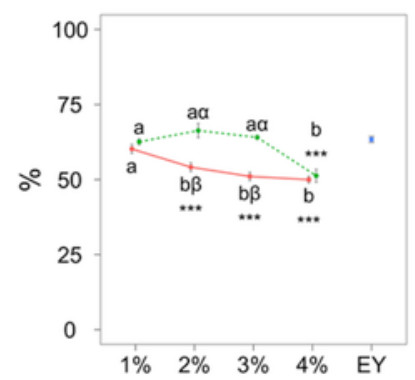

b) Progressive motility

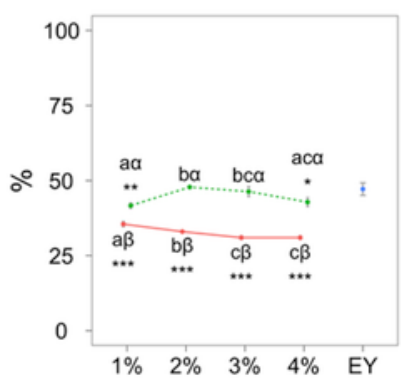

Fig. 3.

The lecithin extenders were made by adding soy lecithin at $1 \%, 2 \%$, $3 \%$ and $4 \%(\mathrm{w} / \mathrm{v})$, termed L1, L2, L3, L4, respectively. The lecithin-based extenders were put in slow shaking for $30 \mathrm{~min}$ in order to get a lecithin emulsion.

Half of each lectithin extender was further processed for making nano-lecithin. In order to achieve a particle size below $100 \mathrm{~nm}$, samples were transferred to a sonicator (mechanical probe sonicator, TOPSONICS, Tehran, Iran) for $45 \mathrm{~min}$. The respective extenders were termed NL1, NL2, NL3 and NL4.

The concentration of glycerol and the freezing procedure were based on a previous study [7]. The semen was extended at room temperature $\left(\sim 25^{\circ} \mathrm{C}\right)$ for $5 \mathrm{~min}$ and then equilibrated at $4{ }^{\circ} \mathrm{C}$ for $2.5 \mathrm{~h}$. The cooled semen was loaded into $0.25-\mathrm{mL}$ French straws (Biovet, L'Agile France) at $5 \times 10^{7}$ spermatozoa/mL [18], then sealed with polyvinyl alcohol powder. The straws were exposed to liquid nitrogen vapors, $4 \mathrm{~cm}$ above the liquid nitrogen for $12 \mathrm{~min}$ [19]. Subsequently, the straws were plunged into the liquid nitrogen for storage. After 2 months, the frozen straws were thawed individually at $37^{\circ} \mathrm{C}$ for $30 \mathrm{~s}$ in a water bath and evaluated. The morphology of nano micelles was assessed by transmission electron microscopy (TEM) (Zeiss Em10C, Germany) using negative staining with $1 \%$ phosphotungstic acid. The mean diameter of the nano micelles formulation was determined based on the dynamic light scattering (DLS) by a Zetasizer system manufactured by Malvern Instruments Ltd. (UK).

\subsection{Evaluation of spermatozoa after thawing}

\subsubsection{Sperm motility}

Sperm motility was measured according to Gil et al. [20]. Three straws from different freezing treatments were thawed at $37^{\circ} \mathrm{C}$ for

$30 \mathrm{~s}$ and pooled in a test tube. Sperm motility was assessed using a computer-assisted sperm analysis system (CASA, Version12 IVOS, Hamilton-Thorne Biosciences, Beverly, MA, USA). Semen samples were diluted $1: 1$ with Tris-buffered medium and incubated at $37^{\circ} \mathrm{C}$ for $10 \mathrm{~min}$. A $3 \mu \mathrm{l}$ drop of the sample was placed on a Leja chamber and evaluated for: Total motility, progressive motility, VCL (curvilinear path velocity), VSL (straight path velocity), VAP (average path velocity), LIN (linearity), STR (straightness), WOB (wobble), and ALH (amplitude of the lateral displacement of the sperm head).

\subsubsection{Plasma membrane integrity}

Plasma membrane integrity was assessed by the eosin-nigrosin stain method. The composition of the stain was: $1.67 \mathrm{~g}$ eosin-Y, $10 \mathrm{~g}$ nigrosin and $2.9 \mathrm{~g}$ sodium citrate, dissolved in $100 \mathrm{ml}$ distilled water. Sperm smears were prepared by mixing a drop of sperm sample with two drops of stain and spreading it with a second slide. Plasma membrane integrity was assessed by counting 200 cells under phase-contrast microscopy (CKX41; Olympus, Tokyo, Japan) at $\times 400$ magnification. Eosin is impermeable to intact plasma membranes, therefore entering and staining non-viable (broken plasma membrane) spermatozoa. Sperm displaying partial or complete purple staining were considered nonviable, whereas spermatozoa showing strict exclusion of the stain (white over nigrosin background) were counted as viable [21].

\subsubsection{Plasma membrane functionality}

The hypo-osmotic swelling (HOS) test was used based on the presence of curled and swollen tails of spermatozoa after a hypo-osmotic treatment. The assay was performed by incubating $10 \mu \mathrm{l}$ of semen with $1 \mathrm{ml}$ of a $100 \mathrm{mOsm} / \mathrm{L}$ hypoosmotic solution $(57.6 \mathrm{mM}$ fructose and $19.2 \mathrm{mM}$ sodium citrate) at $37^{\circ} \mathrm{C}$ for $60 \mathrm{~min}$ at room temperature [22]. The mixture was homogenized and evaluated under an inverted light microscope. A total of 200 spermatozoa were counted in at least five different microscopic fields. The percentage of sperm with swollen and curved tails was recorded [16].

\subsubsection{Sperm abnormalities}

Ten microliters of semen were pipetted into $1.5 \mathrm{ml}$ tubes, containing $1 \mathrm{~mL}$ Hancock's solution [23]. The Hancock's solution was prepared by mixing $62.5 \mathrm{ml}$ formalin ( $37 \%$ formaldehyde), $150 \mathrm{ml}$ sodium saline solution, $150 \mathrm{ml}$ buffer solution and $500 \mathrm{ml}$ double-distilled water. The percentage of sperm abnormalities was recorded by counting 200 spermatozoa under a phase contrast microscope (CKX41; Olympus, Tokyo, Japan).

\section{a) Normal spermatozoa}

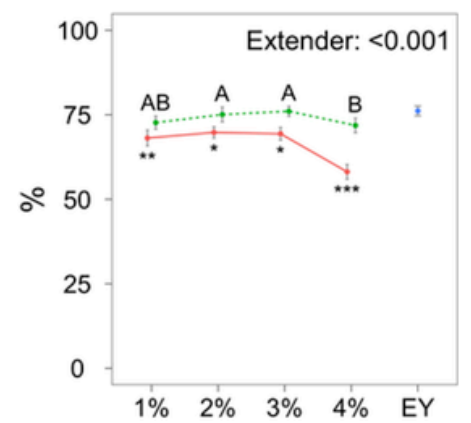

\section{b) Viable spermatozoa $(\mathrm{E} / \mathrm{N})$}

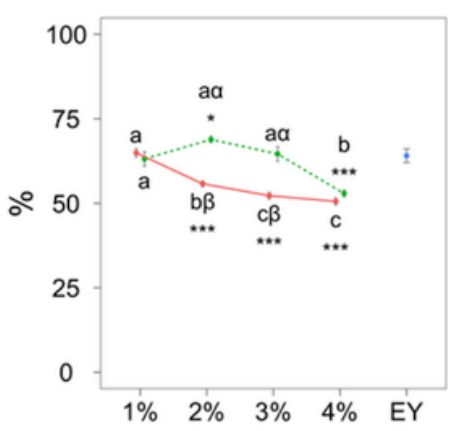

Fig. 4.

\section{c) HOS test}

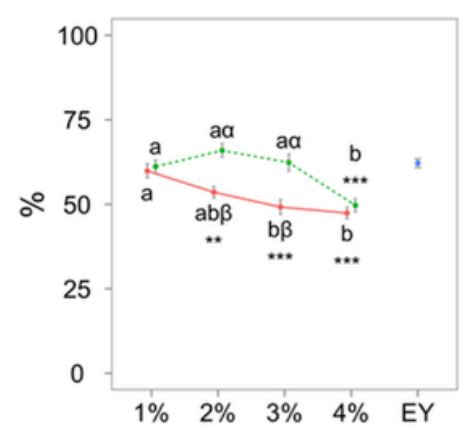




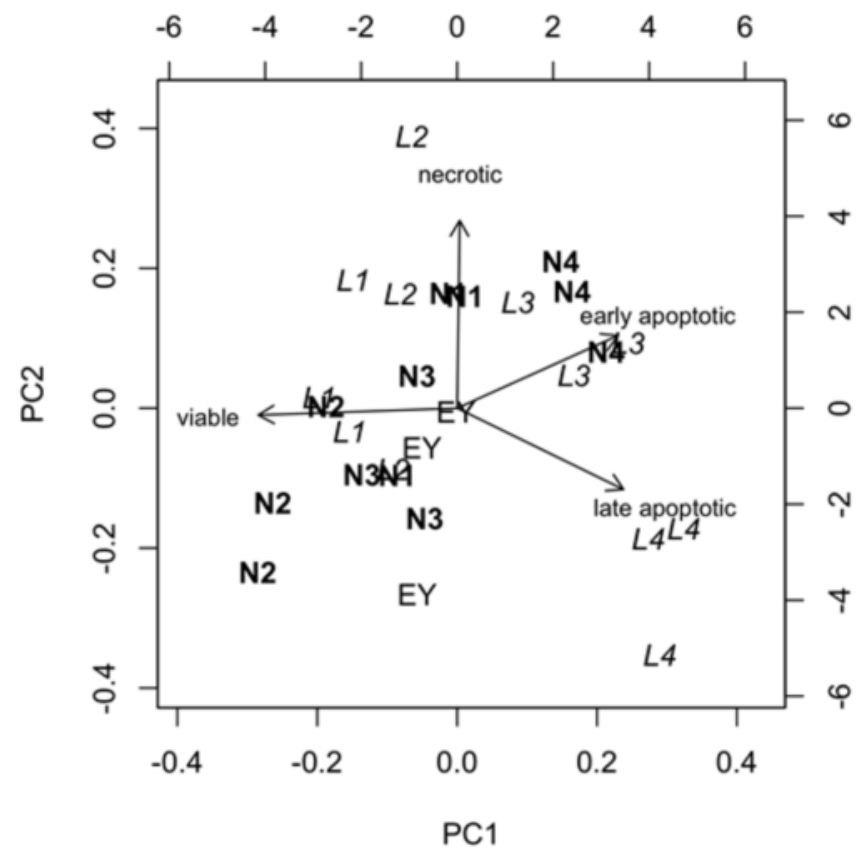

Fig. 5.

Table 3

Comparison of the percentage of cleavage rate and blastocyst formation rate of EY and NL2 (the best treatment is selected based on qualitative parameters) (mean \pm SEM).

\begin{tabular}{lll}
\hline & Proportion of (\%) embryos developed to & blastocyst/oocytes \\
\hline & cleavage & \\
\hline NL2 & $70.83 \pm 3.42$ & $20.83 \pm 1.27$ \\
EY & $68.79 \pm 3.42$ & $21.28 \pm 1.27$ \\
\hline
\end{tabular}

EY: Egg yolk-based extender; NL2: nanolecithin-based extender containing of $2 \%$ of NL.

\subsubsection{Phosphatidylserine (PS) translocation assay}

Apoptosis in post-thaw spermatozoa was evaluated by flow cytometry, using a FACSCalibur flow cytometer (Becton Dickinson, San Jose, CA, USA) [13]. Annexin-V was used to track phosphatidylserine translocation in the sperm plasma membrane. A commercial PS Detection Kit (IQP, Groningen, the Netherlands) was used according to the manufacturer's instructions. Spermatozoa were washed in calcium buffer then centrifuged and $10 \mu \mathrm{l}$ annexin V-FITC was added to $100 \mu \mathrm{l}$ semen suspension, incubating for $15 \mathrm{~min}$ at room temperature. Then, $10 \mu \mathrm{l}$ of propidium iodide (PI) was added to the sperm suspension, and the resultant suspension was analyzed with a Flow cytometer. Following flow cytometry, spermatozoa were classified into four groups as: live spermatozoa (An-/PI-), early-apoptotic spermatozoa (An+/PI-), late-necrotic spermatozoa (An+/PI+) and necrotic spermatozoa $(\mathrm{An}-/ \mathrm{PI}+)$.

\subsubsection{In vitro fertilization (IVF)}

Spermatozoa for IVF trials were obtained from the EY and NL2 treatments (this treatment was selected after the quality assessment as described in Results). Ovaries were recovered from prepubertal ewe lambs at the local slaughterhouse and transported to the laboratory within $1 \mathrm{~h}$ in Dulbecco's PBS at a temperature between $25^{\circ} \mathrm{C}$ and $35^{\circ} \mathrm{C}$ [24]. Occytes were recovered by aspirating cumulus-oocyte complexes (COCs) were cultured in Hepes-buffered TCM 199, peni- cillin-streptomycin $100 \mathrm{IU} / \mathrm{ml}$ and $10 \%(\mathrm{v} / \mathrm{v})$ fetal calf serum (FCS) for $24 \mathrm{~h}$ in $5 \% \mathrm{CO} 2$ at $39^{\circ} \mathrm{C}$ and $100 \%$ humidity [12]. The cumulus-oocyte complexes (COCs) comprised of 4-10 layers of granulosa cells and oocytes with a uniform cytoplasm, homogenous distribution of lipid droplets in the cytoplasm and with an outer diameter of about $90 \mu \mathrm{m}$ (mean) were selected for the experimental procedure [25]. The selected COCs, washed four times in the fertilization medium (FertTALP) before being transferred in groups of 40-50 into $200 \mu 1$ drops of fertilization medium [26]. Three straws of frozen sperm representing one treatment were thawed $\left(37^{\circ} \mathrm{C}, 40 \mathrm{~s}\right)$ and pooled. Motile spermatozoa were obtained by centrifugation at $700 \mathrm{rpm}$, on PureSperm (Nidacon; Gothenburg, Sweden) for $10 \mathrm{~min}$ at room temperature, transferring $2 \times 10^{6}$ spermatozoa $/ \mathrm{ml}$ from the pellet to each droplet of fertilization medium containing 10 matured $\mathrm{COCs}$, and incubated for $24 \mathrm{~h}$ in $5 \% \mathrm{CO}_{2}$ in humidified air at $39^{\circ} \mathrm{C}$ [24]. Cumulus cells were removed from presumptive zygotes by vortexing in $2 \mathrm{ml}$ phosphate buffered saline solution (PBS) for $1 \mathrm{~min}$. In vitro embryo culture was carried out in modified SOF medium [27] containing FCS (10\% v/v) under paraffin oil in a humidified atmosphere of $5 \% \mathrm{CO}_{2}$ and $90 \%$ $\mathrm{N}_{2}$ at $39^{\circ} \mathrm{C}$. The number of cleaved zygotes and embryos reaching the blastocyst stage were recorded at 3 and 7-8 days post-insemination, respectively [28].

\subsubsection{Statistical analysis}

Data were analyzed in the $\mathrm{R}$ statistical environment (www.rproject.com) by linear mixed-effects models, assessing both the effects of the treatments relative to the egg yolk extender and the effects of the two extenders (lecithin and nano-liposome-based extender) and the four concentrations, including the study of their interactions. Annexin V/PI data were also submitted to principal component analysis in order to reduce the complexity of the interpretation from four variables to two principal components. The results of the IVF trial (cleavage and blastocyst development rates) of NL2 and EY were compared with the $\chi^{2}$ Test. Results are shown as mean \pm SEM except otherwise stated.

\section{Results}

The results of size and particle charge and structure of soybean nano-lecithin are presented in Figs. 1 and 2 respectively. Fig. 1a shows that the average particle size used in the present study was $94.6 \mathrm{~nm}$, thus being in the nm range. Fig. $1 \mathrm{~b}$ shows that the nanoparticles had a negative charge. Fig. 2 shows the microstructure of the extender with the nanoparticles.

The total motility (figure 3) was similar between EY and 1-3\% NL $(\mathrm{P}>0.05)$ but significantly decreased when lecithin was added at $2-4 \%$ or at $4 \%$ as nano-lecithin. Progressive motility (figure 3 ) was similarly affected, being significantly lower in all $\mathrm{L}$ respect to $\mathrm{EY}$ and $2-3 \%$ NL (not significant differences among them). Results of the kinematic parameters ( (Table 1) showed an improvement in $2 \% \mathrm{NL}$, with VCL, VSL, LIN, and WOB being significantly higher than in EY. Lecithin extenders and $1 \%$ and $4 \%$ NL showed lower values.

The plasma membrane integrity, plasma membrane functionality (HOS) and the proportion of normal spermatozoa ( Fig. 4) showed small changes between treatments, with EY and 2-3\% NL yielding the highest values. Again, lecithin extenders presented the lowest values, especially at $2-4 \%$.

The analysis of apoptotic features ( Table 2) showed that $2 \%$ NL yielded the highest values for the proportion of viable spermatozoa and the lowest for apoptotic ones, noticeably for late apoptosis $(\mathrm{P}<0.05)$. Sperm apoptosis (early and late) was highest in $3-4 \%$ $\mathrm{L}$ and $4 \%$ NL. Necrotic spermatozoa appeared in a more substantial 
proportion in $1-3 \% \mathrm{~L}$ and $1 \% \mathrm{NL}$. The analysis by principal components (5) showed that the lecithin-based extender $2-4 \%$ and Nano lecithin-based extender $4 \%$ tended to cluster together and in the region corresponding to a higher incidence of apoptotic spermatozoa. Observations corresponding to $2 \%$ and $3 \% \mathrm{NL}, 1 \% \mathrm{~L}$ and egg yolk extenders clustered together in a region corresponding to higher viability and lower apoptosis.

The $2 \%$ NL was selected for comparison to EY in the IVF trial ( Table 3). Both extenders achieved similar results for cleavage and blastocyst formation $(\mathrm{P}>0.05)$.

\section{Discussion}

Our experiments showed that the sperm kinetics and motility parameters of semen declined in all three extenders after freezing-thawing. We demonstrated a differential effect depending on the extender composition, and a good performance of the nano-lecithin formulation, especially at $2 \%$.

The main reason for the decline of sperm motility after cryopreservation are the biochemical and ultrastructural damages produced by the freezing and thawing process [29], which release of free fatty acids [30] and plasmalemma phospholipids is especially relevant [31]. Spontaneous lipid transport is a mechanism whereby lipid molecules move between membranes without any catalytic [32]. Therefore, supplementation with lipid particles, such as LDL from egg yolk or lecithin from nanoparticles of soybean could prevent and even revert this effect. Chelucci et al. (2015) reported that the most effective concentration of lecithin for goat spermatozoa was $1 \%$ [24].

Soybean lecithin nanoparticles at $2 \%$ yielded good results for goat sperm cryopreservation, similarly and even improving results of egg yolk at $15 \%$. Not only $2 \%$ NL yielded good results, but all the nano-lecithin proportions were superior to their lecithin counterparts. We did not test which kind of interactions enabled the nanoparticle protection, but we can pose several hypotheses to test in future studies. Lipid vesicles may prevent lipid losses from the plasmalemma, change its composition or modify the membrane permeability to water and cryoprotective agents [33]. If lecithin nanoparticles alter the permeability of the plasmalemma, it could lead to better penetration of glycerol while facilitating the exit of intracellular water, thus preventing osmotic shock and the formation of ice crystals within the spermatozoa.

The reduction in particle size might increase these effects, possibly because the larger surface-to-volume ratio could facilitate the interaction and beneficial effects of lecithin on spermatozoa, explaining why the nano-lecithin extenders were superior to the lecithin extenders in general. The overall negative charge of nano-lecithin could improve these effects. Upon addition of charged donor vesicles, transfer of negatively charged lipid occurs [34], therefore nanomicelles could have a significant advantage over coarser or larger particles.

The nano-lecithin formulation could act via coating of the sperm plasma membrane [35] or by the interaction of with other extender components. Moreover, we cannot discard that the particles resulting from the simple lecithin suspension could exert a negative effect on the spermatozoa. Interestingly, we noticed a decrease in semen motility and other quality parameters when the proportion of nano-lecithin increased above $3 \%$, which could result from an excessive coating or membrane modifications.

The interaction between seminal plasma and egg yolk are deleterious to goat spermatozoa [36]. Nevertheless, the present study obtained good results when using $15 \%$ egg yolk. The main components of egg-yolk are phosphatidylcholine (PC) and phos- phatidylethanolamine (PE), whereas the main component of the lecithin in the present study was phosphatidylcholine. Therefore, we cannot discard that the performance of egg yolk was due to the presence of a high proportion of phospholipids other than phosphatidycholine. Also, egg yolk contains more saturated fatty acids compared to soy lecithin, potentially having better oxidative stability than soybean lecithin [37]. Salmani et al. [7] reported that $1.5 \%$ of soy lecithin was the most appropriate for freezing goat semen, achieving similar results than $15 \%$ EY. Also, Yodmingkwan et al. (2016) showed that there was no difference in post-thawing quality of Boer goat semen in Tris-fructose-citric acid either with $2.5 \%$ egg yolk or $1.5 \%$ soybean lecithin [38]. However, the present study obtained a lower quality for $1-2 \% \mathrm{~L}$ in the present study compared to the EY. This may be the result of the difference in goat breeds, locations and protocol for preparing soybean lecithin extender which may affect the quality of semen [39].

However, because the lipid composition and fatty acid content of egg yolk differ to that of soy lecithin [37,40], it interacts differently with the lipase enzymes in goat seminal fluid, responsible of toxic effects when using egg yolk as a cryoprotectant [9]. This effect was not apparent in this study but could be the case when cryopreserving goat sperm with other protocols.

The results of the apoptosis assay showed not only an improvement of cell viability in the $2 \% \mathrm{NL}$, but also a significant effect in reducing both early and late apoptotic spermatozoa. However, the other NLs failed in reducing late apoptotic spermatozoa. These findings seem to support the hypothesis that the stabilizing effects of soy lecithin are highly dependent on concentration, and nano-lecithin might be tolerated at a higher concentration. Moreover, apoptotic or necrotic spermatozoa could be detrimental per-se for the viable spermatozoa in the same sample [41], and the reduction of these subpopulations is a very attractive feature of using $2 \% \mathrm{NL}$.

The present study extends our knowledge on the effects of the addition of nanoparticles of soybean lecithin to semen freezing media on spermatozoa functional properties and in vitro fertilizing capacity. The IVF results showed that $2 \%$ lecithin nanoparticles produces no negative effects in oocyte fertilization and blastocyst production, comparing to the standard egg yolk extender. Other studies have shown that the Tris-fructose-citric acid-based extender containing 1.5\% soybean lecithin provided the best motility and viability of the chilled-stored spermatozoa and preserved their fertilization capacity [42].

\section{Conclusions}

The use of a Tris-based extender containing 2\% nanoparticles of soybean lecithin for goat semen cryopreservation seems to be advantageous. The performance of this extender was superior to any of the tested soybean lecithin suspensions and the $15 \%$ egg yolk extender, for which $2 \%$ NL could be a suitable replacement.

\section{Acknowledgments}

The Ministry of Science and the University of Tehran financially supported this research. This study was also granted by University of Tehran under the number 7108017.25.6.

\section{References}

[1] R.H. Hammerstedt, J.K. Graham, J.P. Nolan, Cryopreservation of mammalian sperm: what we ask them to survive, J Androl 11 (1990) 73-88.

[2] I. Grad, Liposomes in gamete and embryo biotechnology, Ann Anim Sci 10 (2010) 3-8. 
[3] J.G. Baust, D. Gao, J.M. Baust, Cryopreservation: an emerging paradigm change, Organogenesis 5 (2009) 90-96.

[4] J. Parks, J. Graham, Effects of cryopreservation procedures on sperm membranes, Theriogenology 38 (1992) 209-222.

[5] M. Beccaglia, P. Anastasi, S. Chigioni, G. Luvoni, Tris-lecithin extender supplemented with antioxidant catalase for chilling of canine semen, Reprod Domest Anim 44 (2009) 345-349.

[6] P. Kumar, M. Saini, D. Kumar, A. Balhara, S. Yadav, P. Singh, et al., Liposome-based semen extender is suitable alternative to egg yolk-based extender for cryopreservation of buffalo (Bubalus bubalis) semen, Anim Reprod Sci 159 (2015) 38-45.

[7] H. Salmani, A. Towhidi, M. Zhandi, M. Bahreini, M. Sharafi, In vitro assessment of soybean lecithin and egg yolk based diluents for cryopreservation of goat semen, Cryobiology 68 (2014) 276-280.

[8] P. Jiménez-Rabadán, M. Ramón, O. García-Álvarez, A. Maroto-Morales, E. Del Olmo, M. Pérez-Guzmán, et al., Effect of semen collection method (artificial vagina vs. electroejaculation), extender and centrifugation on post-thaw sperm quality of Blanca-Celtibérica buck ejaculates, Anim Reprod Sci 132 (2012) $88-95$.

[9] D. Roof, S. Bowley, L. Price, D. Matsas, Comparison of two commercial extenders for cryopreservation of goat semen without sperm washing, Theriogenology 77 (2012) 412-420

[10] H. Salmani, M.M. Nabi, H. Vaseghi-Dodaran, M.B. Rahman, A. Mohammadi-Sangcheshmeh, M. Shakeri, et al., Effect of glutathione in soybean lecithin-based semen extender on goat semen quality after freeze-thawing, Small Rumin Res 112 (2013) 123-127.

[11] I. Valle, A. Gómez-Durán, W. Holt, T. Muiño-Blanco, J. Cebrián-Pérez, Soy lecithin interferes with mitochondrial function in frozen-thawed ram spermatozoa, J Androl 33 (2012) 717-725.

[12] M. Forouzanfar, M. Sharafi, S. Hosseini, S. Ostadhosseini, M. Hajian, L. Hosseini, et al., In vitro comparison of egg yolk-based and soybean lecithin-based extenders for cryopreservation of ram semen, Theriogenology 73 (2010) 480-487.

[13] M. Sharafi, M. Forouzanfar, S.M. Hosseini, M. Hajian, S. Ostadhosseini, L. Hosseini, et al., In vitro comparison of soybean lecithin based-extender with commercially available extender for ram semen cryopreservation, Cell J (Yakhteh) 3 (2009).

[14] M.L. Reed, P.C. Ezeh, A. Hamic, D.J. Thompson, C.L. Caperton, Soy lecithin replaces egg yolk for cryopreservation of human sperm without adversely affecting postthaw motility, morphology, sperm DNA integrity, or sperm binding to hyaluronate, Fertil Steril 92 (2009) 1787-1790.

[15] M. Vick, H. Bateman, W. Swanson, Improved cryopreservation of domestic cat spermatozoa in a soy lecithin-based extender, Reprod Fertil Dev 23 (2010) $153-154$.

[16] R. Nagarajan, "Frozen" micelles: polymer nanoparticles of controlled size by self-assembly, ACS Publications, 2008

[17] I. Pepić, J. Lovrić, A. Hafner, J. Filipović-Grčić, Powder form and stability of Pluronic mixed micelle dispersions for drug delivery applications, Drug Dev Inc Pharm 40 (2014) 944-951.

[18] T. Matsuoka, H. Imai, H. Kohno, Y. Fukui, Effects of bovine serum albumin and trehalose in semen diluents for improvement of frozen-thawed ram spermatozoa, J Reprod Dev 52 (2006) 675-683.

[19] P. Purdy, A review on goat sperm cryopreservation, Small Rumin Res 63 (2006) 215-225.

[20] J. Gil, N. Lundeheim, L. Söderquist, H. Rodríguez-Martínez, Influence of extender, temperature, and addition of glycerol on post-thaw sperm parameters in ram semen, Theriogenology 59 (2003) 1241-1255.

[21] M.N. Bucak, A. Ateșsahin, Ö. Varısslı, A. Yüce, N. Tekin, A. Akçay, The influence of trehalose, taurine, cysteamine and hyaluronan on ram semen: microscopic and oxidative stress parameters after freeze-thawing process, Theriogenology 67 (2007) 1060-1067.

[22] S. Schäfer, A. Holzmann, The use of transmigration and Spermac ${ }^{\mathrm{TM}}$ stain to evaluate epididymal cat spermatozoa, Anim Reprod Sci 59 (2000) 201-211.
[23] A. Najafi, M. Zhandi, A. Towhidi, M. Sharafi, A.A. Sharif, M.K. Motlagh, et al., Trehalose and glycerol have a dose-dependent synergistic effect on the post-thawing quality of ram semen cryopreserved in a soybean lecithin-based extender, Cryobiology 66 (2013) 275-282.

[24] S. Chelucci, V. Pasciu, S. Succu, D. Addis, G.G. Leoni, M.E. Manca, et al., Soybean lecithin-based extender preserves spermatozoa membrane integrity and fertilizing potential during goat semen cryopreservation, Theriogenology 83 (2015) 1064-1074.

[25] F. Berlinguer, M. Madeddu, V. Pasciu, S. Succu, A. Spezzigu, V. Satta, et al., Semen molecular and cellular features: these parameters can reliably predict subsequent ART outcome in a goat model, Reprod Biol Endocrinol 7 (2009) 125

[26] J. Parrish, J. Susko-Parrish, N. First, Effect of heparin and chondroitin sulfate on the acrosome reaction and fertility of bovine sperm in vitro, Theriogenology 24 (1985) 537-549

[27] S.M. Hosseini, F. Moulavi, M. Hajian, P. Abedi, M. Forouzanfar, H.S. Ostad, et al., Highly efficient in vitro production of bovine blastocyst in cell-free sequential synthetic oviductal fluid vs. TCM199 Vero cell co-culture system, 2008.

[28] M. Sharafi, M. Forouzanfar, S.M. Hosseini, M. Hajian, S. Ostadhosseini, L. Hosseini, et al., In vitro comparison of soybean lecithin based-extender with commercially available extender for ram semen cryopreservation, Int J Fertil Steril 3 (2009).

[29] V.A. Aires, K.-D. Hinsch, F. Mueller-Schloesser, K. Bogner, S. Mueller-Schloesser, E. Hinsch, In vitro and in vivo comparison of egg yolk-based and soybean lecithin-based extenders for cryopreservation of bovine semen, Theriogenology 60 (2003) 269-279.

[30] B.C. White, J.G. Wiegenstein, C.D. Winegar, Brain ischemic anoxia: mechanisms of injury, JAMA 251 (1984) 1586-1590.

[31] A. Darin-Bennett, A. Poulos, I. White, The effect of cold shock and freeze-thawing on release of phospholipids by ram, bull, and boar spermatozoa, Aust J Biol Sci 26 (1973) 1409-1420

[32] S. Lev, Non-vesicular lipid transport by lipid-transfer proteins and beyond, Nat Rev Mol Cell Biol 11 (2010) 739.

[33] T. Röpke, H. Oldenhof, C. Leiding, H. Sieme, H. Bollwein, W. Wolkers, Liposomes for cryopreservation of bovine sperm, Theriogenology 76 (2011) $1465-1472$.

[34] J.L. Richens, A.I. Tyler, H.M. Barriga, J.P. Bramble, R.V. Law, N.J. Brooks, et al., Spontaneous charged lipid transfer between lipid vesicles, Sci Rep 7 (2017) 12606

[35] J. Ricker, J. Linfor, W. Delfino, P. Kysar, E. Scholtz, F. Tablin, et al., Equine sperm membrane phase behavior: the effects of lipid-based cryoprotectants 1 , Biol Reprod 74 (2006) 359-365.

[36] C. Gangwar, S. Kharche, S. Kumar, S. Jindal, Cryopreservation of goat semen: status and prospects, Indian J Small Ruminants 22 (2016) 1-10.

[37] L.E. Palacios, T. Wang, Egg-yolk lipid fractionation and lecithin characterization, J Am Oil Chem Soc 82 (2005) 571-578.

[38] P. Yodmingkwan, S. Guntaprom, J. Jaksamrit, K. Lertchunhakiat, Effects of extenders on fresh and freezing semen of boer goat, Agric Agric Sci Procedia 11 (2016) 125-130.

[39] B. Leboeuf, B. Restall, S. Salamon, Production and storage of goat semen for artificial insemination, Anim Reprod Sci 62 (2000) 113-141.

[40] J. Le Grandois, E. Marchioni, M. Zhao, F. Giuffrida, Sd Ennahar, Bindler Fo, Investigation of natural phosphatidylcholine sources: separation and identification by liquid chromatography - electrospray ionization - tandem mass spectrometry (LC- ESI- MS2) of molecular species, J Agric Food Chem 57 (2009) 6014-6020.

[41] J. Roca, I. Parrilla, M.A. Gil, C. Cuello, E.A. Martinez, H. Rodriguez-Martinez, Non-viable sperm in the ejaculate: lethal escorts for contemporary viable sperm, Anim Reprod Sci 169 (2016) 24-31.

[42] S. Yotov, Effect of TFC-based extenders with soybean lecithin and/or low concentration of glycerol on the quality of goat chilled-stored semen, Int J Curr Microbiol Appl Sci 4 (2015) 752-761. 